\title{
ERMITA INMACULADA CONCEPCIÓN, EL LLANO DE ALAJUELA. RESEÑA DEL PROCESO DE RESTAURACIÓN
}

\author{
Ileana Hernández Salazar \\ Instituto Tecnológico de Costa Rica
}

Recibido: 31-08-2016

Aprobado: 22-10-2016

Ileana Hernández Salazar.
Arquitecta por la Universidad
de Costa Rica, 2007. Máster en
Conservación del Patrimonio
Arquitectónico por la
Universidad Politécnica de
Valencia, España, 2013.
Miembro de ICOMOS Costa
Rica desde el año 2014.
Directora Técnica para IEF S.A
en proyectos de restauración
de edificios patrimoniales
desde 2014. Profesora de la
Escuela de Arquitectura y
Urbanismo del Instituto
Tecnológico de Costa Rica
desde 2016.
chaliukbua@gmail.com

\section{Resumen}

A lo largo de casi un siglo desde su construcción y a pesar de sufrir el embate del paso del tiempo, la Ermita de la Inmaculada Concepción en El Llano de Alajuela, es un ejemplar significativo de la arquitectura vernácula costarricense. Fue durante muchos años centro de culto y referente dentro de la organización urbana y social de la comunidad, donde la mayor parte de sus habitantes, son descendientes directos de quienes por los años de 1880, decidieron construir con tierra de sus patios y con esfuerzo y sacrificio personal, un templo donde vivir las tradiciones populares y religiosas de los cuales eran herederos.

Como parte de los recientes esfuerzos en materia de conservación y rescate de las construcciones patrimoniales, el Centro de Investigación y Conservación del Patrimonio Cultural de Costa Rica, destinó recursos económicos para realizar el proyecto de restauración de esta Ermita, construida con adobe, bahareque, calicanto, ladrillo y teja. El proceso de intervención tuvo una duración de 4 meses y se realizó siguiendo los procedimientos dictados por las normativas patrimoniales, cuyo objetivo principal es devolverle al inmueble su esplendor y conservarlo como digno representante de la tradición constructiva en Costa Rica.

Palabras clave: Arquitectura de tierra, Ermita, Restauración, El Llano.

\begin{abstract}
Nearly a century since its construction and despite suffering the onslaught of time, the Church of the Immaculate Conception in El Llano de Alajuela, is a great representative of Costa Rican vernacular architecture. It was for many years a center of worship and reference in urban and social organization of the community, where most of its inhabitants are direct descendants, of those for the years 1880 decided to build with earth and effort and personal sacrifice, a church for we live their popular and religious traditions.

As part of recent efforts in conservation and rescue of heritage buildings, the Center for Research and Conservation of Cultural Heritage of Costa Rica, allocated financial resources for the restoration project of this vernacular building, built with adobe, wattle and daub, masonry, brick and tile. The intervention process lasted four months and its main objective was to restore the church and preserve it as an important example of the building tradition in this country.
\end{abstract}

Key Words: Earthen architecture, Church, Restoration, El Llano. 


\section{HISTORIA}

La Ermita del Llano ubicada en la provincia de Alajuela es más que un pequeño centro de oración, es la síntesis del sentimiento de un pueblo, un sueño de ciudadanos que se convirtió en realidad cuando el último bloque de adobe se colocó, marcando el comienzo de una iglesia que vería entre sus muros, las vivencias de toda una población, las alegrías, las tristezas, las uniones, el sentir de su fe cristiana.

Tras la fundación de la ciudad de Alajuela en el año de 1782, se conformaron cinco barrios principales. El Llano, fue tan solo un caserío, perteneciente a los "Targuaces", también conocido como "La Concepción". La mayoría de la población que habitaba el sitio se dedicaba, en conjunto, a la agricultura y la ganadería, reforzando aún más el carácter humilde de sus habitantes. Por otra parte, los pobladores al no contar con un lugar para recibir los sacramentos litúrgicos o para reunirse en oración, debían acudir a la Agonía de Alajuela para participar de dichos oficios.

Por comodidad, estos "llaneros" -como antiguamente se les conocióconcibieron la idea de crear un lugar de culto cercano a sus casas, así como un sitio donde celebrar las fiestas en honor a La Purísima Concepción. Es así como el 16 de agosto de 1881, la propuesta de edificar una pequeña iglesia en El Llano fue aceptada por los principales líderes religiosos del momento. Los terrenos fueron donados por doña Eusebia Solana Sibaja allá por los años de 1880, aunque otras fuentes de la época, citan que una de las manzanas fue donada por José María Sibaja (El Cencerro, 20 agosto, 1881).

Muchas son las fechas que se citan alrededor de la finalización del templo, sin embargo, se puede afirmar que la construcción fue consumada antes de la década de los 90 del siglo XIX. El presupuesto para la construcción fue obtenido por los mismos moradores de El Llano de muy diversas maneras, muchos colaboraron como propia mano de obra, por medio de la donación de diversos materiales o gracias a la realización de fiestas, turnos, rifas, entre otras muchas actividades. Asimismo, como colaboración por parte de la municipalidad de Alajuela, se declaró que todas las ganancias que se obtuvieran de las mencionadas fiestas, se destinarían, íntegras, a la construcción de la Ermita, eximiendo así a los organizadores, de los derechos de pago por la venta de licores y alimentos. 
Durante la construcción y una vez finalizadas las obras, se recibieron algunas visitas del obispo Thiel-Hoffman, para corroborar el avance de los trabajos e incluso para plantear ciertas recomendaciones religiosas sobre el buen uso del inmueble. Tras finalizarse la construcción, hubo algunas reformas para perfeccionar su estado final o añadir mejoras al edificio, siendo las más señaladas la colocación del pavimento interior de baldosa hidráulica, el cielo raso metálico y más adelante, las campanas, las cuales fueron trasladadas en la década de los 80 del siglo XX, a la nueva iglesia que se erigió al costado norte de la histórica Ermita. Esta misma suerte sufrieron otros de sus muebles, tales como las imágenes religiosas, mientras que bancas y retablos menores, se perdieron por el paso del tiempo. Finalmente, en años posteriores se construyó una bodega hacia el costado sur y un hermoso y funcional empedrado en el sector este.

Otro aspecto importante a destacar es que debido a lo iconográfico de su arquitectura, la Ermita de El Llano ha sido fondo y decoración para no pocos escritores, haciendo que sus personajes corriesen aventuras bajo la sombra de sus anchos muros de tierra. Además, ha sido morada para los "pasitos" navideños tradicionales de todos los años, así como otros hechos religiosos patrocinados por la comunidad y eventos de carácter más social y folclórico, como las salidas de los tradicionales payasos, al recorrer las calles del barrio.

\section{DESCRIPCIÓN DEL TEMPLO}

El edificio es primordialmente de adobe, con planta de cruz latina aunque originalmente se trató de una edificación de nave única. Los brazos están compuestos por dos sacristías, ambas comunicadas con el presbiterio por medio de 2 puertas macizas de madera. Dichas estancias cuentan con accesos desde el exterior y una ventana pequeña. El brazo sur del templo posee otro espacio adicional que se corresponde con una pequeña bodega, cuyos paramentos fueron edificados con bahareque en una intervención posterior. Es este elemento añadido el que interrumpe lo que pudo haber sido inicialmente, una construcción simétrica.

Coexisten además, materiales como el calicanto y el ladrillo y un piso de baldosa hidráulica como pavimento interior. La Ermita posee una cubierta a tres aguas, elaborada con teja, la cual fue colocada sobre láminas de hierro galvanizado, sustentadas por sencillas cerchas de 
madera. Bajo estas piezas se encuentra el cielo raso también de madera, rematado con una cornisa decorada del mismo material.

La fachada principal se compone de tres entradas de arcos de medio punto, coronados en sus tímpanos por pequeños vitrales. Hacia el tercio superior se observa una serie de cornisas y pilastras, rematadas por dos pináculos, colocados en ambos extremos en de la fachada. Completa el conjunto, un pequeño campanil, construido con posterioridad, de base cuadrada y decoración austera, coronado por medio de una cúpula de estructura de madera y lámina metálica lisa con remaches sobre la que se instaló una modesta cruz.

La nave principal de la iglesia está iluminada por medio de 4 ventanas ubicadas 2 a cada lado de la nave, rematadas con arcos de medio punto, sobre los cuales se instalaron sencillos vitrales multicolor. El presbiterio por su parte, alberga el altar mayor iluminado por una pequeña ventana

El color predominante es el blanco en la totalidad de las paredes a excepción del zócalo exterior donde se utilizó un tono celeste y algunos elementos de la fachada principal que utilizan este mismo color para pilastras y los arcos de medio punto. Además, se destaca el uso de este mismo tono para destacar las marqueterías de madera al interior y exterior del inmueble. Por último, para la cúpula se empleó un tono rojizo oscuro como elemento contrastante.

\section{CONSIGNACIÓN DE PATOLOGÍAS}

La Ermita de El Llano a pesar del escaso mantenimiento en los últimos años y tras ser testigo de numerosos movimientos sísmicos, sufrir el embate de agentes climatológicos e incluso ser blanco de eventos vandálicos, se había mantenido sin presentar patologías estructurales que afectaran su estabilidad, no obstante, esos mismos agentes que la habían azotado con el devenir de los años, originaron ciertas patologías que poco a poco habían deteriorado algunas partes del edificio y habían contribuido a opacar la belleza de esta arquitectura tradicional.

Los problemas principales que presentaba el edificio previo al proceso de restauración fueron los siguientes: 


\section{Erosión de revestimiento}

Los revestimientos además de dar acabado, confieren protección a las estructuras interiores de las paredes. Los muros que están expuestos a las inclemencias meteorológicas, Iluvia, radiación solar y viento, sufren patologías relacionadas con el desgaste. Las paredes localizadas en el sector este de la Ermita y primordialmente el costado sur de la bodega de bahareque, presentaban pérdida del revestimiento en la mayor parte del muro.

\section{Reposición con mortero de cemento}

La utilización de morteros de cemento para reparaciones en estructuras de barro, cierra los poros de los muros, impidiendo la circulación de la humedad y generando una degradación progresiva difícilmente identificable hasta que los desprendimientos se producen. Constituye una práctica habitual, aunque considerablemente dañina. En el caso de la Ermita, existían algunos lugares que habían sido revestidos utilizando morteros de cemento, la mayor parte de ellos en las paredes interiores de la nave central

\section{Desprendimiento del revestimiento}

Consiste en la separación por pérdida de adherencia, entre el revestimiento y el muro. Suele producirse como consecuencia de lesiones previas o fisuras no reparadas que tras algún tiempo de permanecer expuestas, facilitan la entrada de humedad. Fue considerada la patología más extendida en la Ermita, abarcaba desde los muros interiores, hasta los paramentos exteriores de las bodegas y la sacristía.

\section{Suciedad y desgaste de pavimento interior}

La nave central presenta dos tipos de pavimentos distintos, la primera parte es colorida con presencia de motivos geométricos en tonos azules, mientras que la segunda parte -la mayor en área ya que cubre la sacristía y la bodega nortecuenta con una tonalidad más clara y con geometría a base de pequeños triángulos azules. El uso continuado, el alto tránsito, la utilización de productos abrasivos para la limpieza, ocasionaron lesiones de carácter superficial en las baldosas. Se 
identificó una importante costra de suciedad común a todos los espacios y grandes zonas con un acusado desgaste.

\section{Filtraciones en la cubierta}

La falta, desplazamiento o rotura de cualquiera de los elementos que conforman la cubierta, son las principales causas para que se origine un problema de estanqueidad. El viento, los movimientos sísmicos y el tránsito de personas por la cubierta, facilitan el desplazamiento de las tejas y originan las filtraciones. En este caso, se identificaron numerosas filtraciones, ubicándose la mayoría de ellas en las áreas más cercanas a las cumbreras.

\section{Pudrición de las maderas}

Dentro de las principales causas que originan esta patología está el aumento de la humedad en la madera, la cual suele provenir de la condensación o de filtraciones de la cubierta. Otro agente que consume las maderas es la termita, propia de lugares húmedos y cálidos y el ataque de hongos que colonizan la madera al ver ésta incrementados sus niveles de humedad, principalmente en áreas poco ventiladas o directamente en contacto con la tierra o el agua de lluvia. Este tipo de problema se detectó en la cuerda superior de la cercha principal, en la puerta de la bodega sur y en dos de las columnas de la nave, poniendo en riesgo parte de la estabilidad de la estructura de la cubierta a la que dan soporte.

\section{Grietas en los muros}

La causa radica fundamentalmente, en la falta de traba entre los muros. Esta patología se encuentra localizada en prácticamente todos los encuentros entre muros perpendiculares, lo que nos lleva a concluir que en primera instancia, se edificó la nave y posteriormente se le añadieron los brazos. Otro tipo de agrietamiento presente fue el que surge por flexión, ocasionando aberturas longitudinales que se pueden identificar en las construcciones de adobe durante o después de un movimiento sísmico. Esta abertura en la pared se presenta como una leve fisura, similar a las que se presentan en el revestimiento, sin embargo, se desprende éste y se pone de 
manifiesto la profundidad y la intensidad del daño. Esta patología se encontró localizada únicamente en un sector del muro lateral norte de la nave central.

\section{PROCESO DE RESTAURACIÓN}

Desde la construcción del nuevo templo en los años ochenta, la Ermita perdió trascendencia como escenario de actividades religiosas, por lo que fue utilizado por la comunidad, en fechas significativas para la realización de algunas actividades específicas, tales como los Rosarios Del Niño, procesiones de Semana Santa, o las fiestas en honor a la Virgen de la Purísima Concepción, Patrona a la que está dedicada la Ermita.

Como consecuencia del interés y profunda identificación que los vecinos mantienen hacia este inmueble, se conformó la Comisión Para la Restauración del Templo, encargada de la organización de diversas actividades de carácter social, que generaran recursos económicos para las labores de intervención del edificio. No obstante, el presupuesto superaba por muchas cifras, los números que barajaba la organización, por lo que en una partida importante, el Centro de Investigación del Patrimonio Cultural del Ministerio de Cultura y Juventud, aportó el dinero, por medio de licitación pública, para la ejecución del proceso de restauración.

Las actuaciones llevadas a cabo en la Ermita del Llano fueron las siguientes:

\section{Etapa 1. Revestimiento}

Se trabajó sobre el revestimiento de los muros de adobe y bahareque tanto interiores como exteriores. Se eliminó por completo todo el repello que cubría los muros del templo y se realizó un nuevo repello de barro. La elaboración de la mezcla se realizó de la manera tradicional en el sitio, utilizando además, fibras naturales secas

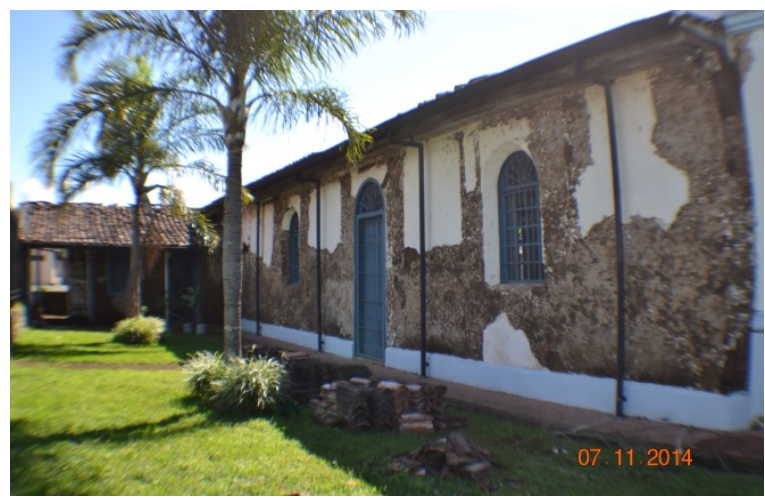

Fig. 1: Ermita El Llano. Retirada de repellos de cemento. Autor: Archivo personal, 2015

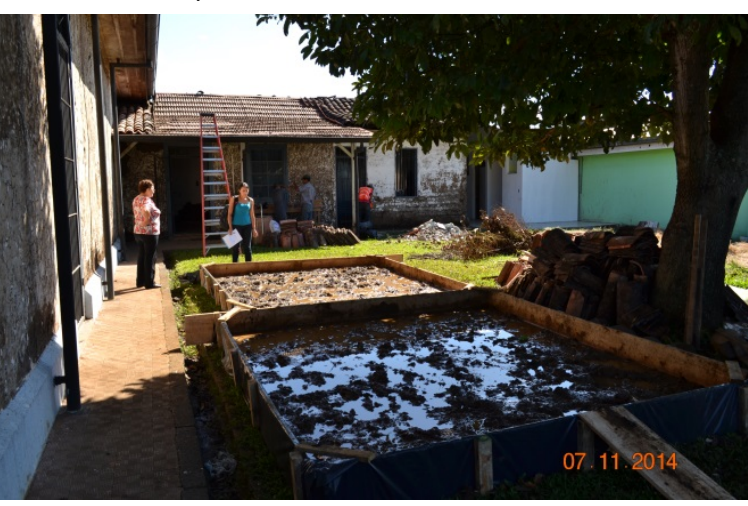

Fig. 2: Ermita El Llano. Proceso de preparación del barro. Autor: Archivo personal, 2015. 
picadas muy finamente (zacate de pitilla) y respetando el tiempo de fermentación que originalmente necesitaba la composición (Fig. 1 y 2). Una vez restituido el revestimiento, se aplicó el acabado final, mediante la elaboración de la mezcla utilizando cal, agua y aglomerante natural (tuna) en condiciones similares al procedimiento tradicional. El color de todas las paredes de barro fue el blanco, tal y como tradicionalmente se ha utilizado en esta construcción.

\section{Etapa 2. Paredes nuevas de bahareque}

Fue necesaria la sustitución total de las paredes de la bodega sur, por lo que las existentes se demolieron. Se ejecutó la estructura de madera y caña brava (previo tratamiento) colocando las piezas de la misma manera en que se encontraban originalmente. La elaboración de la mezcla de barro se realizó de la manera tradicional en el sitio, como se describió en la etapa 1. El llenado de los muros se realizó a la manera tradicional empleando tiestos de barro. Las paredes tuvieron

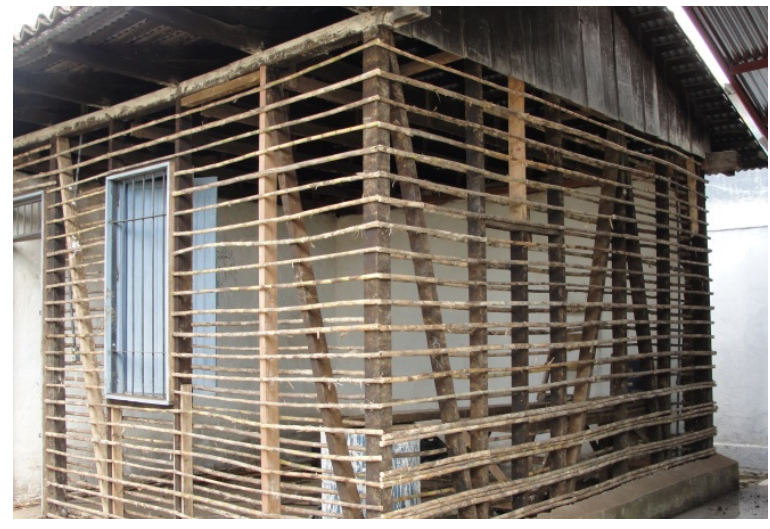

Fig. 3: Ermita El Llano. Construcción de nuevas paredes. Autor: Archivo personal, 2015.

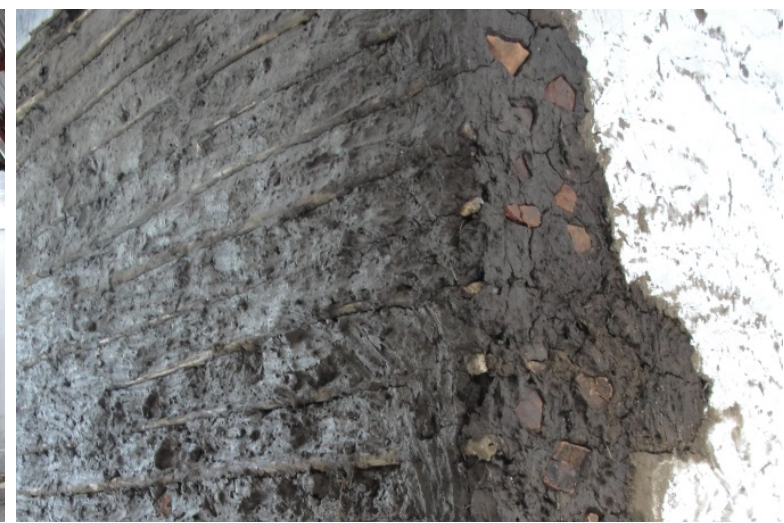

Fig. 4: Ermita El Llano. Elaboración de pared de bahareque. Autor: Archivo personal, 2015.

un tiempo de secado y finalmente se repellaron y encalaron (Fig. 3 y 4).

\section{Etapa 3. Mejoramiento de la traba y desplome de muro}

Una vez se retirado por completo el revestimiento se verificaron las fisuras de los muros. Se identificó una grieta importante y un desplome de parte del muro sur de la nave en su encuentro con la sacristía. Para solventar este problema se realizaron unas pequeñas rozas en el muro sur y en el muro perpendicular de la sacristía, para 
colocar 2 piezas de madera de cedro debidamente curadas, desde las que se insertaron 4 varillas de acero tratadas para mejorar la traba de los muros. Finalmente se dio acabado al igual que al resto de las paredes de la Ermita (Fig. 5).

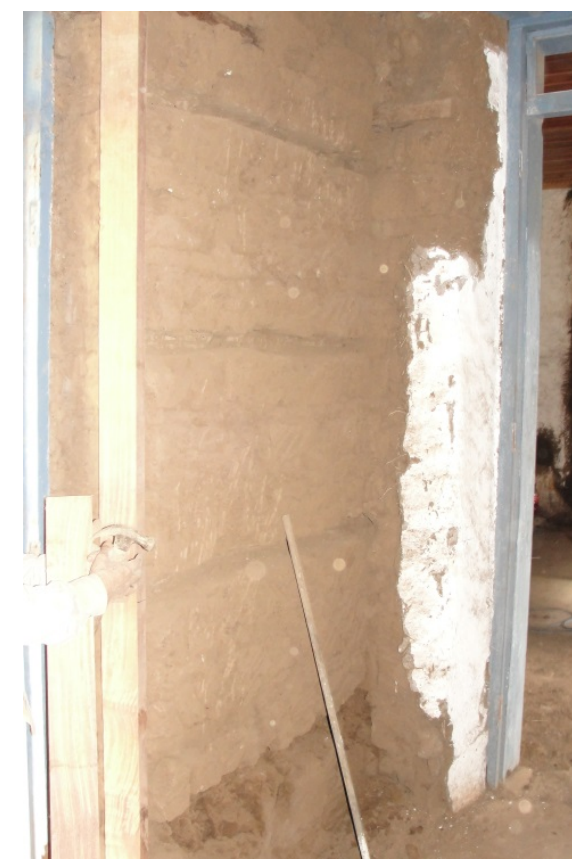

Fig. 5: Ermita El Llano. Mejora de la traba Autor: Archivo personal, 2015.

\section{Etapa 4. Sustitución de elementos de madera}

Se sustituyeron dos columnas de la nave central con serios problemas por ataque de termitas. Dicha patología ponía en riesgo la estabilidad de la estructura ante el futuro. Para dicha sustitución se empleó madera de cedro debidamente seca. Los cortes para el reemplazo de las piezas se realizaron en la parte superior e inferior y su adherencia se dio por medio del uso de adhesivos tradicionales. Finalmente, para lograr una integración visual de las nuevas piezas con la madera original, se empleó un acabado con un barniz de color claro.

\section{Etapa 5. Tratamiento}

Debido a la agresión de xilófagos y termitas en algunas estructuras de madera de la cubierta y algunas columnas de la nave principal se aplicó un tratamiento general para todas las maderas del edificio. Dicha aplicación se realizó por aspersión.

\section{Etapa 6. Limpieza de pavimento hidráulico}

La limpieza de las baldosas sucias que conforman la nave principal, sacristía, bodega y corredores noroeste y suroeste representaba un problema debido a su sensibilidad ante los productos abrasivos, por lo que el procedimiento se realizó manualmente por medio de un cepillado en seco inicialmente y en húmedo posteriormente. Como acabado final se aplicó cera para pisos. 


\section{Etapa 7. Tratamiento pavimentos exteriores}

Algunas losetas de color rojo requerían de limpieza por medios mecánicos, es decir, utilizando cepillo y agua. Para el tratamiento de las lagunas, se elaboró una reposición mediante mortero de cal y colorante natural rojo (Ocre), siguiendo la línea guía del pavimento.

\section{Etapa 8. Restauración de la cubierta de teja}

Se realizó la limpieza de la cobertura de tejas, retirando la suciedad acumulada de tipo orgánico o artificial: escombros, nidos, hojas, entre otros elementos de tamaño considerable (Fig. 6 y 7 ).

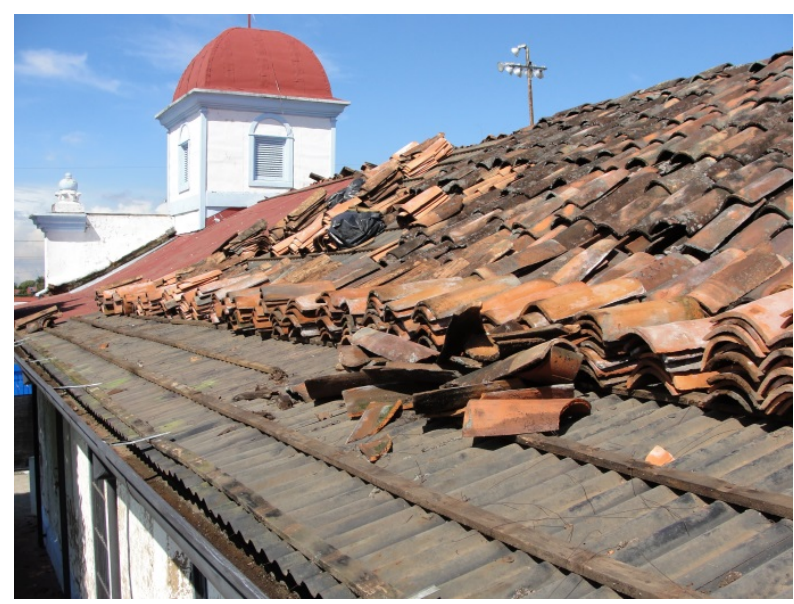

Fig. 6: Ermita El Llano. Trabajo en cubierta de teja. Autor: Archivo personal, 2015.

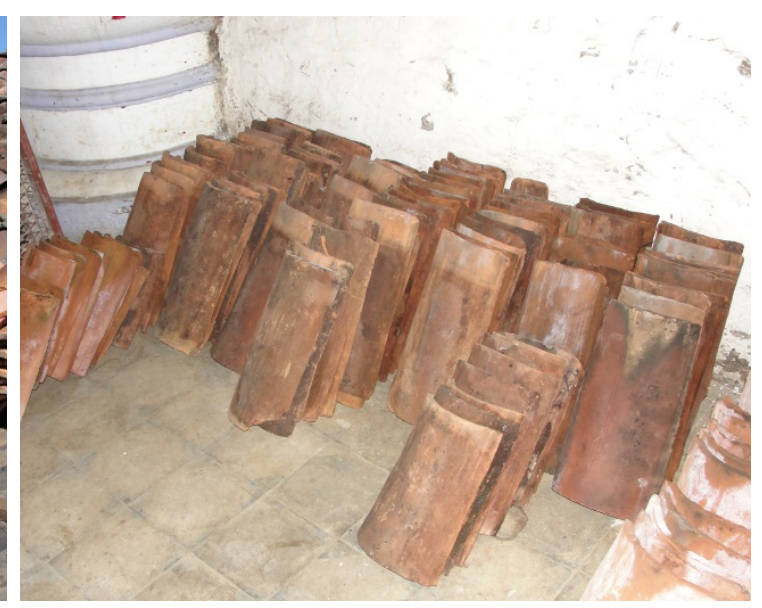

Fig. 7: Ermita El Llano. Tratamiento a tejas de barro. Autor: Archivo personal, 2015.

Seguidamente se retiraron los tramos de tejado, limpiándolas manualmente con cepillo y agua y aplicándoles el sellador respectivo. Posteriormente se sustituyeron las piezas de madera de soporte, por piezas de hierro galvanizado y se elaboraron gachos de alambre galvanizado para la sujeción de las tejas. Finalmente éstas fueron recolocadas en su sitio.

\section{Etapa 9. Tratamiento de elementos metálicos}

El primer paso consistió en realizar un decapado de las superficies oxidadas, mediante la utilización de lana de acero. Una vez limpios los elementos, se les aplicó una capa de anticorrosivo y finalmente el acabado con pintura base agua. 


\section{Etapa 10. Reconstitución de carpinterías}

La exposición continuada y la falta de mantenimiento apropiado afectaron las carpinterías, mostrándose en la aparición de fendas y cuarteados entre otras. En primer lugar se retiraron las piezas de madera y se nivelaron empleando formones. A continuación se prepararon las piezas a insertar en las áreas faltantes, utilizando madera de cedro. Seguidamente se limpiaron mecánicamente para retirar el polvo y el aserrín suelto, se extendió la cola de adhesión y tras el periodo de espera recomendado, se reposicionaron las piezas en su sitio. El acabado final se dio por medio de pintura base acuosa, aplicada con brocha.

\section{CONCLUSIONES}

El objetivo tras la restauración es que la Ermita continúe albergando todas las actividades que históricamente el pueblo ha desarrollado en ella, es decir, celebraciones religiosas importantes como la Fiesta de la Inmaculada Concepción y las fiestas navideñas, lugar para la realización de El Huerto durante la Semana Santa, así como punto de partida para celebraciones tradicionales. Se pretende además, que la Ermita, tal como fue en el pasado, sea la columna vertebral de la vida de "los Llaneros", un lugar en el que gire la vida del barrio, que le devuelva su importancia en la vida de la comunidad.

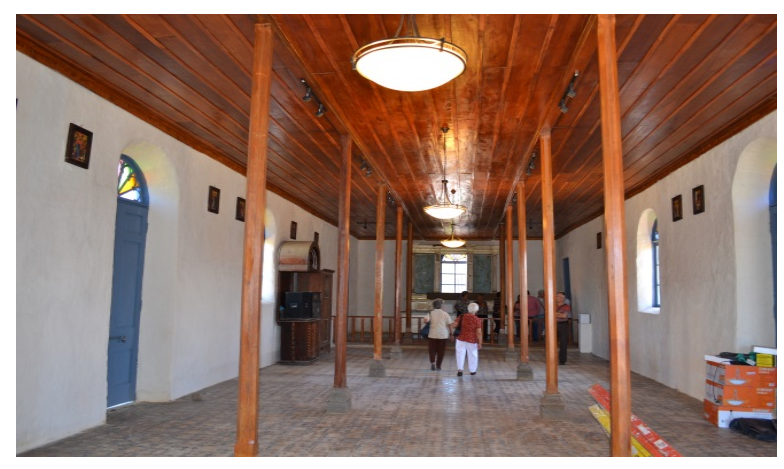

Fig. 8: Ermita El Llano. Acabado final interior. Autor: Archivo personal, 2015.

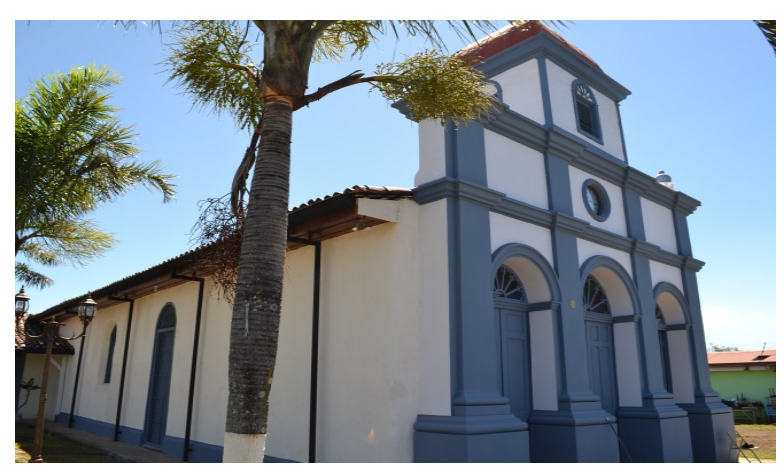

Fig. 9: Ermita El Llano. Acabado final fachada principal. Autor: Archivo personal, 2015.

Por otra parte, conscientes de que un edificio con uso esporádico no es el mejor escenario para el mantenimiento adecuado del mismo y que la musealización no es la única opción para los inmuebles patrimoniales, se propuso convertir al edificio en un lugar cultural 
cuyas funciones que le permitiesen generar ingresos propios para su adecuado mantenimiento y preservación.

La restauración de la Ermita del Llano de Alajuela, fue un proceso de aprendizaje para toda una comunidad, un ejemplo de amor por el patrimonio y un reto en cuanto al rescate de técnicas constructivas prácticamente olvidadas. Tras las labores de intervención, los vecinos consientes de la trascendencia de su lucha por el rescate de tan emblemático inmueble, continúan con las labores de mantenimiento del edificio, el cual es utilizado como locación para la elaboración de cortometrajes, centro de actividades culturales e incluso se ha empezado a utilizar como escenario de bodas y eventos sociales (Fig. 8 y 9).

\section{BIBLIOGRAFÍA}

Cátedra. (Ed.). (2012). Diccionario Visual de Términos Arquitectónicos (2a ed). Madrid: Grupo Anaya.

Fonseca, E. y Garnier, E. (1998). Historia de la Arquitectura en Costa Rica. San José: Fundación Museos del Banco Central de Costa Rica.

Milleto, C. y Vegas, F. (2011). Aprendiendo a Restaurar. Un Manual de Restauración de la Arquitectura Tradicional de la Comunidad Valenciana. Valencia: Colegio Oficial de Arquitectos de la Comunidad Valenciana.

Hernández Salazar, I. (2013). Restauración de Arquitectura de Tierra en Zonas Sísmicas. El caso de Costa Rica. Tesis de Fin de Máster, Universidad Politécnica de Valencia. Valencia.

Cerdas, A. y Tellini, Z. (1985). Iglesia de la Concepción del Llano de Alajuela. Boletín Informativo del Centro de Investigación y Conservación del Patrimonio Cultural 3(3), 13-16.

\section{ARCHIVOS}

Archivo Histórico Arquidiocesano. Fondos Antiguos. Documentación Encuadernada 1881. Caja 285.

Archivo Histórico Arquidiocesano. Fondos Antiguos. Libro Copiador de Notas para los Señores Curas i Tenientes de Cura 1881. 
Archivo Histórico Arquidiocesano. Fondos Antiguos. Visitas Pastorales Augusto Thiel.

Archivo Histórico Arquidiocesano. Cuentas Parroquia de Alajuela.

Archivo Histórico Arquidiocesano. Eco Católico. Emisario del Clero.

Archivo Histórico Arquidiocesano. Inventario e Índice del libro de Documentos Pontificios 1926-1980. Número 21. Folio 49.

\section{Listado de imágenes}

Figura 1: lleana Hernández Salazar (2015). Proceso de Restauración Ermita de El Llano, Alajuela. Disponible en Archivo Personal.

Figura 2: lleana Hernández Salazar (2015). Proceso de Restauración Ermita de El Llano, Alajuela. Disponible en Archivo Personal.

Figura 3: Ileana Hernández Salazar (2015). Proceso de Restauración Ermita de El Llano, Alajuela. Disponible en Archivo Personal.

Figura 4: Ileana Hernández Salazar (2015). Proceso de Restauración Ermita de El Llano, Alajuela. Disponible en Archivo Personal.

Figura 5: Ileana Hernández Salazar (2015). Proceso de Restauración Ermita de El Llano, Alajuela. Disponible en Archivo Personal.

Figura 6: lleana Hernández Salazar (2015). Proceso de Restauración Ermita de El Llano, Alajuela. Disponible en Archivo Personal.

Figura 7: lleana Hernández Salazar (2015). Proceso de Restauración Ermita de El Llano, Alajuela. Disponible en Archivo Personal.

Figura 8: lleana Hernández Salazar (2015). Proceso de Restauración Ermita de El Llano, Alajuela. Disponible en Archivo Personal.

Figura 9: lleana Hernández Salazar (2015). Proceso de Restauración Ermita de El Llano, Alajuela. Disponible en Archivo Personal. 